\title{
nature
}

\section{Due process or French farce?}

France's 'contaminated blood' trial is a reminder that witch-hunts, how ever well dis guised in legal formalities, are no substitute for a credible, wide-ranging and dis pas sionate judicial inquiry.

$\mathrm{B}$ ritain's judicial inquiry into the causes of its bovine spongiform encephalopathy (BSE) crisis may be belated, but it is at least being carried out thoroughly, rigorously and dispassionately (see Nature 392, 532; 1998). The contrast with France's long-running contaminated blood affair could not be more stark.

In the latest round, three former ministers, including former prime minister Laurent Fabius, went on trial in Paris last week charged with 'involuntary homicide' for their handling of the threat of HIV infection of the blood supply in 1985 (see page 548). They are accused in particular of delaying the introduction of a US AIDS test - to screen blood donations - to protect the market for a French test.

The trial has quickly turned to farce. Verdicts will be delivered by a group of parliamentary judges in the Court of Justice of the Republic, a court created specially to try the ministers. But so far, instead of proceeding with a detailed blow-by-blow analysis of the chronology of the affair and the many complex issues involved, the court has engaged in ad hoc questioning of the defendants and witnesses. Matters have not been helped by the performance of the president, who visibly lacks an adequate grasp of the dossier.

The resulting dire lack of serious cross-examination has rightly prompted protests from victims infected with HIV via transfusions, and their families, who feel that justice may not be done. Justice for the defendants may also fail to emerge: even if judged innocent, the questionable legal procedures mean that public suspicion of their guilt will hang over them for the rest of their days.

This sad state of affairs was fairly predictable. The government, its advisory committees and medical institutions have been justifiably forced by the media and the judiciary to account for their actions. But the subsequent criminalization of the whole issue has served no one.
Confusing things further is the fact that what is on trial is not simply the actions of individuals that led to the blood scandal, but the entire system of a ruling élite and its advisers, usually graduates of the prestigious grandes écoles and considered removed from the interests of the people.

Also, as so often in this affair, the media are conducting their own fringe trial in the corridors of the court. The atmosphere remains so emotionally charged that cold scientific arguments by the defence, no matter how sound, cannot hope to compete with the impact of a televised interview with a mother who has lost her child to AIDS through a blood transfusion. Reason and science have gone out of the window, and the cherished principles of the serenity of justice and presumption of innocence have been trampled upon.

Scientists who have testified to the extenuating circumstances of the mid-1980s have too often been summarily rejected as merely bidding to absolve the guilt of those in positions of responsibility at the time. Michel Setbon, a French researcher, told the court last week that his research showed that "there is no relationship of cause and effect between the introduction of the diagnostic tests and the [level] of contaminations".

If he is right, the prosecution's case may already be in tatters. More enlightening, however, would have been an independent analysis of not just this aspect, but the entire complex affair. But none of the various trials have commissioned independent expert reports, relying instead on documents often removed from their wider context and the sometimes dubious recollections of testifying experts. There is a danger that the saga will yield neither justice nor the lessons that need to be drawn on handling risk and scientific uncertainty if France is to avoid similar tragedies in the future.

\section{Food for thought}

A row over genetic ally modified foods spotlights the importance of procedures for validating scientific data.

If the stakes were not so high, there would also be something farcical about the past week's media circus in Britain over the potential health risks of genetically modified (GM) crops. Six months ago, Arpad Pusztai, a research scientist at the Rowett Research Institute in Scotland, was temporarily suspended after allegedly misleading the media about the potential health impacts of eating genetically modified foods, based on his (unpublished) studies of rats fed potatoes modified to produce lectin. Now, accompanied by even bigger headlines, a group of his colleagues has endorsed his (still unpublished) conclusions, fanning an already heated debate over a possible moratorium on the commercial growing of all GM crops (see page 547).

The concerns at the centre of the debate are certainly genuine. Given the widespread - and rapidly growing — use of GM products in the food of the average consumer, any indication of a health risk that has not been properly characterized would be a source of major concern. Memories of the BSE crisis, and the continuing reassurances of government officials and scientists that British beef was safe, remain fresh. And, like the nuclear issue, much of the opposition to GM foods rests on legitimate worries that an enthusiasm for a new technology may have blunted sensibilities to - and encouraged secrecy about - its potential dangers.

But this is a case for intensive monitoring, not a complete ban or even a moratorium. It is also a case for a hard-headed scientific appraisal of evidence and its potential implications, not yet more science by press conference. Philip James, the head of the Rowett Institute - and a respected nutrition researcher - is correct to have reduced the heat of the current debate by opening the available scientific data to public scrutiny. Less understandable are his provocative actions against Pusztai last summer.

There are several lessons to be learnt. One is the reinforcement of the need for the promised Freedom of Information Act; suspicion thrives on a culture of secrecy that is whipped up by stories of scientists being 'gagged'. The media need a better understanding of the difference in credibility between published and unpublished 'scientific' data. And an independent body needs to be set up to assess available (even if preliminary) evidence of the potential dangers of GM foods before full commercialization proceeds. The lessons of BSE have yet to be fully absorbed. 